\title{
Effect of Dexmedetomidine on Hemodynamics in Thoracic Surgery - A Randomized Controlled Study
}

\author{
Shweta Agarwall, ${ }^{1, *}$, Reetu Verma ${ }^{2}$, Aparna Shukla $^{2}$, Hemlata $^{2}$, Dinesh Singh ${ }^{2}$, Ajay Kumar Chaudhary ${ }^{2}$
}

${ }^{1}$ Department of Anaesthesiology, Hind Institute of Medical Sciences, Lucknow, Uttar Pradesh, INDIA.

${ }^{2}$ Department of Anaesthesiology, KGMU, Lucknow, Uttar Pradesh, INDIA.

\begin{abstract}
Background: Thoracotomy is associated with various hemodynamics consequences that are influenced by the position of the patient's body on the operation Table and metabolic functions of lungs. Dexmedetomidine is an alpha-2 agonist sedative-analgesic that inhibits endogenous norepinephrine release and has been used in various studies to maintain intraoperative hemodynamic stability. Aim: To evaluate the effect of Dexmedetomidine infusion on hemodynamics during thoracic surgery. Methods: The selected patients were randomly allocated to the two groups (39 patients in each group) using a computer-generated random number table. Group $D$ patients received initial bolus of Dexmedetomidine $1 \mathrm{\mu gm} / \mathrm{kg}$ in $100 \mathrm{ml}$ normal saline over $15 \mathrm{~min}$ before induction followed by intravenous infusion of dexmedetomidine @ $0.5 \mu \mathrm{gm} / \mathrm{kg} / \mathrm{hr}$ intraoperatively. Group P received initial $100 \mathrm{ml}$ normal saline over $15 \mathrm{~min}$ given prior to induction followed by infusion of Propofol @ $200 \mu \mathrm{gm} / \mathrm{kg} / \mathrm{min}$ intraoperatively. Statistics: All analysis was performed on SPSS (Windows version 16). Results: In this study, it was observed that use of dexmedetomidine result in less rise in MAP and heart rate at the time of intubation as well as at the time of extubation in comparison to propofol $(p<0.05)$. Episodes of bradycardia was more in D Group as $12.8 \%$ patients required atropine for bradycardia compared to only $2.5 \%$ in group P. As well as more patients in Group D received mephentermine for hypotension. The intraoperative requirement of fentanyl was also more in group P. Conclusion: Initial bolus of Dexmedetomidine $1 \mathrm{\mu g} / \mathrm{kg}$ 15 min before induction followed by intravenous infusion of Dexmedetomidine @ $0.5 \mu \mathrm{g} / \mathrm{kg} / \mathrm{hr}$ decreases the stress response during DLT intubation and extubation but more patients in dexmedetomidine group required atropine or mephentermine for bradycardia and hypotension.
\end{abstract}

Key words: Double Lumen Tube, Mean Arterial Pressure, Propofol.
Article Information

Received: 11-05-2021

Revised : 12-06-2021

Accepted: 29-07-2021

Correspondence

Dr Shweta Agarwal

Assistant Professor, Hind Institute of Medical Sciences,Lucknow,Uttar Pradesh, INDIA.

Phone: +91-8577859842

E-mail: drshwetaagarwal1987@gmail.com,

\section{INTRODUCTION}

Thoracic anesthesia is a challenging subspecialty because during thoracotomy various hemodynamic and oxygenation (hypoxemia and increased shunt fraction) changes occur. The hemodynamic changes are affected by position of patient and metabolic

\section{Access this article online}

\begin{tabular}{|l|c|}
\hline \multirow{2}{*}{$\begin{array}{l}\text { Website: } \\
\text { www.jcramonline.com }\end{array}$} & Quick Response code \\
\hline 10.5530/jcram.1.1.2 & \\
&
\end{tabular}

functions of lungs. The metabolic functions lead to increased release of catecholamines in the lungs that causes increased total peripheral resistance and arterial pressures. ${ }^{1}$ The anesthetist is also faced with the additional demands of establishing lung isolation. Double lumen tube is most commonly used for this purpose but significant pressor response to endobronchial intubation does occur. ${ }^{2}$

Total intravenous anesthesia (TIVA) using propofol and opioid reduce stress response in comparison to inhalational anesthetic-based anesthesia during pulmonary resection ${ }^{3}$ and it has been observed that propofol as a continuous intravenous infusion is a satisfactory alternative during thoracic surgery. ${ }^{4}$ 
Dexmedetomidine is an alpha-2 agonist sedativeanalgesic that inhibits endogenous norepinephrine release and it has been found effective in attenuating the cardiovascular response to single-lumen endotracheal tube as well as double lumen tube intubation and maintaining intraoperative hemodynamic during intraoperative period. ${ }^{5-9}$

Sheikh TA et al. compared effects of intravenous dexmedetomidine and propofol infusion on hemodynamics and postoperative outcomes in cardiac surgery and observed that heart rate and MAP were significantly less in dexmedetomidine group. ${ }^{10}$ In a study done by Chattopadhyay $\mathrm{U}$ et al. it was observed that dexmedetomidine is comparable with propofol in maintaining anesthesia and it can produce better control of hemodynamics and BIS value and can be used as the sole maintenance anesthetic agent. ${ }^{11}$

We hypothesized that intravenous dexmedetomidine infusion during thoracic surgery would result in a less rise in MAP and heart rate in comparison to propofol infusion. So, the present study was done to compare the effects of Dexmedetomidine infusion with propofol infusion on hemodynamics during thoracic surgery. The primary objective of the study was to compare effects of dexmedetomidine and propofol infusion on MAP and heart rate at intubation and extubation as well as intraoperatively. The secondary objectives were to observe side effects like hypotension and bradycardia.

\section{METHODS}

After getting approval from Ethical committee, a prospective randomized, single blind study was conducted in patients aged 18-60yrs of either sex belonging to ASA physical status I, II and III and within $25 \%$ of ideal weight and height who were posted for elective anterolateral thoracotomies in a tertiary care hospital in the period of August 2014-August 2015. Informed consent was taken from each patient in his or her own language. The patients excluded were: patients having any cardiovascular disease (complete heart block), renal, liver, endocrine, neurological disease, known history of allergy to study medication, pregnant and lactating females, patient suffering from neuromuscular disease, patients taking diuretics, calcium channel blocker, steroid, antiepileptic and ACE inhibitors.

ASA fasting guidelines were followed and patients were prepared for elective OT. After taking the patient in OT an intravenous line is secured. Heart rate (H.R.), mean blood pressure (MAP), end tidal $\mathrm{CO}_{2}\left(\mathrm{EtCO}_{2}\right)$, oxygen saturation $\left(\mathrm{SPO}_{2}\right)$, temperature and 12-lead ECG monitoring was done. Patients were premedicated with injection (inj.) glycopyrrolate $(0.2 \mathrm{mg}$ i.v.) and inj. fentanyl $(2 \mu \mathrm{g} / \mathrm{kg}$ i.v. $)$ and thereafter fentanyl was given every hourly@1 $1 \mu \mathrm{gm} / \mathrm{kg}$ intravenously (i.v.) during the surgery. The selected patients were randomly allocated into the two groups (39 patients in each group) using a computer-generated random number table. Group $\mathrm{D}$ patients received initial bolus of Dexmedetomidine $1 \mu \mathrm{g} / \mathrm{kg}$ in $100 \mathrm{ml}$ normal saline over $15 \mathrm{~min}$ before induction followed by intravenous infusion of Dexmedetomidine @ $0.5 \mu \mathrm{g} / \mathrm{kg} / \mathrm{hr}$. Group P received initial $100 \mathrm{ml}$ normal saline over $15 \mathrm{~min}$ given prior to induction followed by infusion of Propofol @ $200 \mu \mathrm{gm} / \mathrm{kg} / \mathrm{min}$. After preoxygenation with 100\% oxygen for $3 \mathrm{~min}$ patients in both groups were induced with Propofol (1-2mg/kg i.v.). After giving Succinylcholine $(2 \mathrm{mg} / \mathrm{kg}$ i.v.), laryngoscopy was done and patients were intubated with double lumen endotracheal tube using standard technique. The same anesthesiologist performed all intubations. Intubation time i.e., time from laryngoscopy to tracheal cuff inflation was recorded. After clinical confirmation of its correct placement along with $\mathrm{EtCo}_{2}$ monitoring, long-acting muscle relaxant Vecuronium $(0.1 \mathrm{mg} / \mathrm{kg}$ i.v. $)$ was given and mechanical ventilation was started. The Patient's position was maintained in lateral decubitus with diseased lung on upper side. One of the two lumens of DLT was blocked and one lung ventilation was started. Anesthesia was maintained with oxygen/air mixture,

Table 1: CONSORT 2010 Flow Diagram.

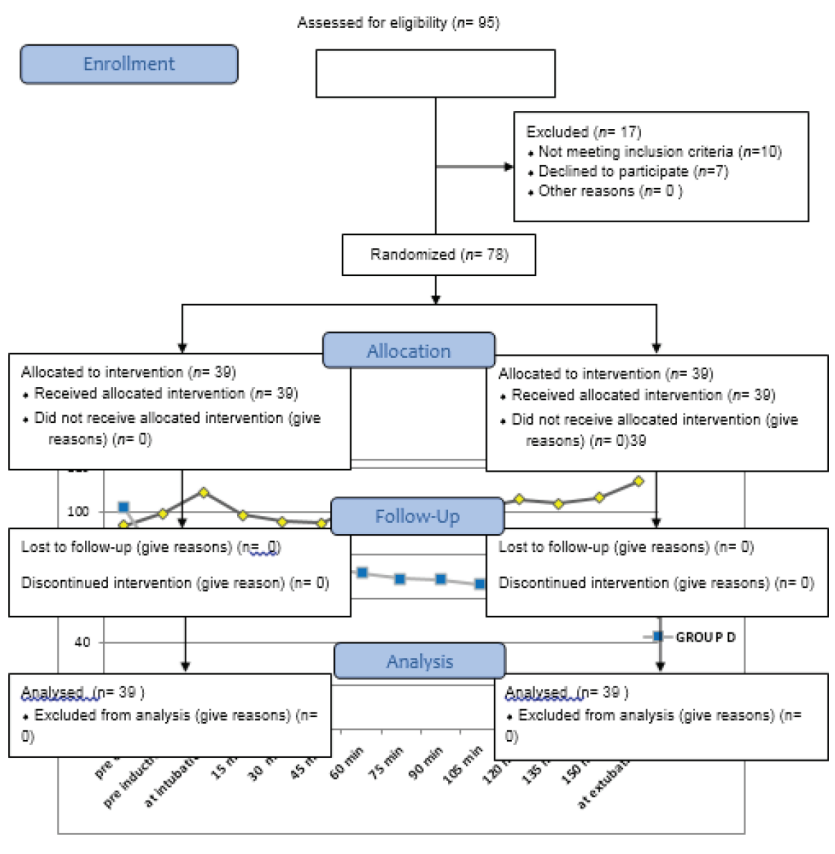


intravenous anesthetic drugs and muscle relaxants. Intravenous infusions of the drugs under study were started through infusion pumps according to their study groups. Drug preparation- $=$ Group P- $50 \mathrm{ml}$ of propofol $(10 \mathrm{mg} / \mathrm{ml})$ was taken in $50 \mathrm{ml}$ syringe and infusion started with infusion pump at desired rate and titrated in accordance with clinical parameters. Group D- $1 \mathrm{ml}$ of dexmedetomidine $(100 \mu \mathrm{g} / \mathrm{ml})$ was diluted in $49 \mathrm{ml}$ of normal saline in $50 \mathrm{ml}$ syringe and infusion started with infusion pump at desired rate and titrated in accordance with clinical parameters. Infusion was continued till the end of the surgery up to closure of skin incision. At the end of surgery reversal neostigmine $0.05 \mathrm{mg} / \mathrm{kg}$ with glycopyrrolate $(0.01 \mathrm{mg} / \mathrm{kg})$ was given intravenously and patients were extubated on return of spontaneous respiration and consciousness. The clinical parameters heart rate (HR), mean arterial pressure (MAP), $\mathrm{SpO}_{2}$ were monitored before induction, at the time of intubation and then at $15 \mathrm{~min}$ intervals till the end of the surgery and at the time of extubation. In this study, if patient's heart rate dropped to $\leq 50 \mathrm{bpm}$, dexmedetomidine or propofol infusion rate was decreased to half or stopped if required and $0.5 \mathrm{mg}$ atropine was given. If systolic blood pressure was $\leq 90 \mathrm{mmHg}$ or MAP $\leq 65 \mathrm{mmHg}$, dexmedetomidine and propofol infusion rates were decreased to half or stopped if required, and $6 \mathrm{mg}$ bolus mephentermine was given. Total requirement of atropine and mephentermine were noted. If the patient was having tachycardia $>100 / \mathrm{min}$ ruling out other causes injection fentanyl $1 \mu \mathrm{gm} / \mathrm{kg}$ bolus was given. Total requirement of fentanyl was recorded. Blood transfusion was done in accordance to blood loss.

Statistical analysis: Continuous data were summarized as Mean \pm SD while discrete (categorical) in $\%$. The categorical variables were compared by chi-square $(\chi 2)$ test continuous variables were compared by ANOVA. A two-sided $(\alpha=2) p<0.05$ was considered statistically significant. All analysis was performed on SPSS (window version 16).

\section{RESULTS}

The demographic profile was comparable between the two groups. (Table 2).

In our study, we have observed a statistically significant effect of a dexmedetomidine loading dose and infusion on MAP and heart rate during intubation, intraoperatively as well as at the time of extubation $(p<0.05)$ (Figures 1 and 2). There was a decrease in heart rate after giving the loading dose of dexmedetomidine as compared to the preoperative values. On intravenous infusion,
Table 2: Patient Characteristics and Intraoperative Variables.

\begin{tabular}{cccc}
\hline & $\begin{array}{c}\text { Group P } \\
(\boldsymbol{n}=39)\end{array}$ & $\begin{array}{c}\text { Group D } \\
(\boldsymbol{n}=\mathbf{3 9 )}\end{array}$ & $\boldsymbol{p}$-value \\
\hline Mean Age (years) & $30.05 \pm 11.46$ & $27.77 \pm 11.66$ & 0.386 \\
Male: Female & $31: 8$ & $34: 5$ & 0.362 \\
ASA Grade I:II:III & $13: 15: 11$ & $9: 19: 11$ & 0.549 \\
Mean Height $(\mathrm{cm})$ & $159.25 \pm 9.54$ & $161.33 \pm 9.58$ & 0.341 \\
Mean Weight $(\mathrm{kg})$ & $52.08 \pm 8.03$ & $52.90 \pm 8.46$ & 0.662 \\
Mean BSA $\left(\mathrm{kg} / \mathrm{m}^{2}\right)$ & $1.50 \pm 0.13$ & $1.53 \pm 0.14$ & 0.461 \\
\hline
\end{tabular}

${ }^{*} p<0.05=$ Significant

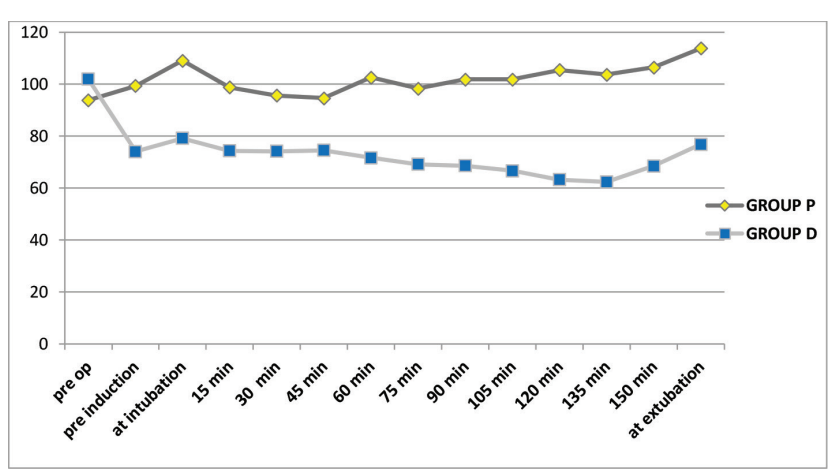

Figure 1: Comparison of heart rate (per minute) between the groups.

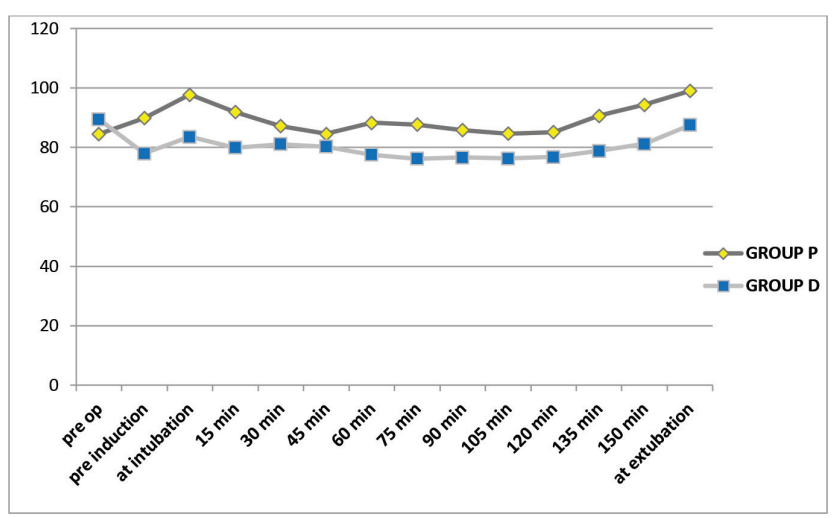

Figure 2: Comparison of mean arterial pressure (MAP in $\mathrm{mmHg}$ ) between the groups.

this decrease in heart rate was well maintained though out the surgery even on intubation and at surgical incision. But in-group P there was an increase in heart at the time of intubation. The rise in heart rate was $16 \%$ from baseline and 10\% from pre-induction time. At the time of extubation, heart rate was increased in both groups but this increment was less in patients receiving dexmedetomidine infusion as compared to group $\mathrm{P}$ and difference was found to be statistically significant $(p=0.00)$. Mean arterial pressure was more stabilized in the dexmedetomidine group as compared 
to the group $\mathrm{P}$ and there was a statistically significant difference in the values between the two groups. Similarly, there was an increase in mean blood pressure at the time of intubation in group $\mathrm{P}$ but it was within $20 \%$. This increase in blood pressure was 15\% from baseline and 9\% from pre-induction time. Episodes of bradycardia was more in D Group as $12.8 \%$ patients required atropine for bradycardia compared to only $2.5 \%$ in group P. As well as more patients in Group D received mephentermine for hypotension. The intraoperative requirement of fentanyl was also more in group P. (Table 3).

Significant $(p<0.05)$ difference was observed between the groups in $\mathrm{SpO}_{2}$ intraoperatively, but it was clinically insignificant as $\mathrm{SpO}_{2}$ remained $94-99 \%$ in the intraoperative period in both groups (Figure 3).

\section{DISCUSSION}

In our study we have observed the effects of dexmedetomidine infusion on hemodynamics with one lung ventilation during thoracic surgery and it was observed that there was a statistically significant difference in MAP and heart rate in both groups.

Table 3: Clinical particulars.

\begin{tabular}{cccc}
\hline & $\begin{array}{c}\text { Group } \\
\mathbf{P}(\boldsymbol{n}=39)\end{array}$ & $\begin{array}{c}\text { Group } \\
\mathbf{D}(\boldsymbol{n}=39)\end{array}$ & $\boldsymbol{p}$ - value \\
\hline $\begin{array}{c}\text { Intubation time in } \\
\text { seconds }\end{array}$ & $21.15 \pm 3.21$ & $21.23 \pm 2.86$ & 0.91 \\
$\begin{array}{c}\text { No. of patients } \\
\text { required Atropine } \\
\text { No. of patients } \\
\text { required } \\
\text { mephentermine } \\
\text { Intraoperative } \\
\text { fentanyl }\end{array}$ & $1(2.5 \%)$ & $5(12.8 \%)$ & .089 \\
requirement $(\mu \mathrm{gm})$ & $89.10 \pm 30.6$ & $69.6 \pm 22.5$ & $.002^{*}$ \\
\hline
\end{tabular}

$* p<.05=$ Significant

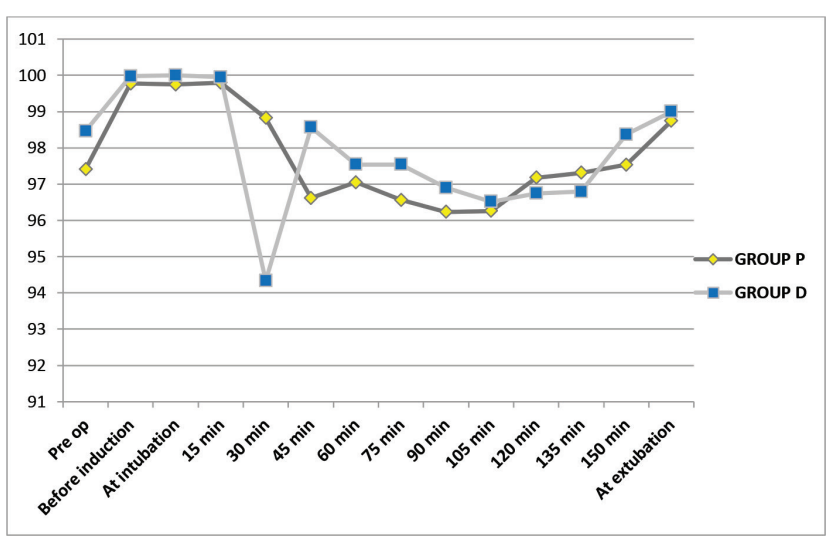

Figure 3: Comparison of $\mathrm{SpO}_{2}$ between the groups.
Dexmedetomidine is an $\alpha-2$ agonist drug that inhibits the release of norepinephrine from the central nervous system and has sympatholytic effects. Pipenmekaporn $\mathrm{T}$ et al. observed that prophylactic dexmedetomidine infusion attenuates the hemodynamic responses to laryngoscopy and DLT intubation. ${ }^{7}$ In our study we have also observed that in dexmedetomidine group increase in heart rate and MAP at critical times like DLT insertion and extubation were significantly less as compared to group P. In addition to its direct sedativeanalgesic properties, dexmedetomidine also reduces opioid requirements and minimum alveolar concentration levels for inhalational anesthetics. ${ }^{12,13} \mathrm{We}$ also observed that intraoperative requirement of fentanyl was less in dexmedetomidine group. In thoracic surgery, dexmedetomidine may offer several physiologic benefits. It reduces the sympathetic response to surgical stimulus which may provide cardio protective benefits. ${ }^{14}$ As we have also observed that with dexmedetomidine infusion, the heart rate was well maintained $(60-75 \mathrm{bpm})$ throughout the surgery even at intubation and at surgical incision. Similarly, Patel CR et al. also observed that dexmedetomidine infusion maintains hemodynamic stability and attenuates the stress responses. ${ }^{15}$

Dexmedetomidine, although generally well-tolerated in the absence of co-morbid cardiovascular disease, bradycardia and hypotension have been reported in the adult population. ${ }^{15,16}$ Patel CR et al. observed in their study that the incidence of bradycardia was $6.66 \%$ with the use of dexmedetomidine and that was managed by giving injection atropine. ${ }^{15}$ But in our study $12.8 \%$ patients required atropine. The high incidence of bradycardia in our surgery may be because of different nature of surgery. Also, in our study more patients receiving dexmedetomidine required mephentermine $(28.20 \%$ vs $7.69 \%)$. Similarly a cohort study done by Kernan et al. in which dexmedetomidine infusion was used in one lung ventilation and in their study more patients in dexmedetomidine group required phenylephrine to maintain the blood pressure in comparison to placebo group (66.6\% vs $30 \%)$. ${ }^{17}$ They also observed that dose of phenylephrine was higher in dexmedetomidine group as compared to placebo group. In this study it was observed that $\mathrm{SPO}_{2}$ remained $94-99 \%$ in intraoperative period in both groups. Lee $\mathrm{SH}$ et al. have found that dexmedetomidine infusion along with sevoflurane intraoperatively improves oxygenation and lung mechanics in patients with moderate COPD undergoing lung cancer surgery. ${ }^{18}$ $\mathrm{Xia} \mathrm{R}$ et al. also observed that intravenous infusion of dexmedetomidine along with isoflurane inhalation 
significantly reduces the degree of increase in intrapulmonary shunt. ${ }^{19}$

This study has some limitations like tachycardia and hypertension are used as surrogate for light level of anesthesia and have not used BIS for monitoring the depth of anaesthesia. Another limitation is that it is a single centre study.

To be concluded, Dexmedetomidine infusion results in less rise in MAP and heart rate during DLT intubation and extubation but more patients in dexmedetomidine group required atropine and mephentermine for bradycardia and hypotension.

\section{CONCLUSION}

Dexmedetomidine infusion results in less rise in MAP and heart rate during DLT intubation and extubation but more patients in dexmedetomidine group required atropine and mephentermine for bradycardia and hypotension during intraoperative period.

\section{CONFLICT OF INTEREST}

The authors declare that there is no conflict of interest.

\section{ABBREVIATIONS}

DLT: Double Lumen Tube; MAP: Mean Arterial Pressure; HR: Heart Rate.

\section{REFERENCES}

1. Kittnar O. Cardiac preload: hemodynamic physiology during thoracic surgery. Curr Opin Anaesthesiol. 2011 Feb;24(1):21-3. doi: 10.1097/ ACO.0b013e328341ab9b, PMID 21084980.

2. Yoo KY, Jeong CW, Kim WM, Lee HK, Jeong S, Kim SJ, Bae HB, Lim DY, Chung SS. Cardiovascular and arousal responses to single-lumen endotracheal and double-lumen endobronchial intubation in the normotensive and hypertensive elderly. Korean J Anesthesiol. 2011;60(2):90-7. doi: 10.4097/kjae.2011.60.2.90, PMID 21390163.

3. Jung SM, Cho CK. The effects of deep and light propofol anesthesia on stress response in patients undergoing open lung surgery: a randomized controlled trial. Korean J Anesthesiol. 2015;68(3):224-31. doi: 10.4097/ kjae.2015.68.3.224, PMID 26045924.

4. Sharifian Attar A, Tabari M, Rahnamazadeh M, Salehi M. A comparison of effects of propofol and isoflurane on arterial oxygenation pressure, mean arterial pressure and heart rate variations following one-lung ventilation in thoracic surgeries. Iran Red Crescent Med J. 2014;16(2):e15809. doi: 10.5812/ircmj.15809, PMID 24719749.

5. Kunisawa $T$, Nagata $O$, Nagashima M, Mitamura $S$, Ueno M, Suzuki $A$, Takahata O, Iwasaki H. Dexmedetomidine suppresses the decrease in blood pressure during anesthetic induction and blunts the cardiovascular response to tracheal intubation. J Clin Anesth. 2009 May;21(3):194-9. doi: 10.1016/j. jclinane.2008.08.015, PMID 19464613.
6. Menda F, Köner O, Sayin M, Türe H, Imer P, Aykaç B. Dexmedetomidine as an adjunct to anesthetic induction to attenuate hemodynamic response to endotracheal intubation in patients undergoing fast-track CABG. Ann Card Anaesth. 2010;13(1):16-21. doi: 10.4103/0971-9784.58829, PMID 20075530.

7. Pipanmekaporn T, Punjasawadwong Y, Charuluxananan S, Lapisatepun W, Bunburaphong $P$. The effect of prophylactic dexmedetomidine on hemodynamic disturbances to double-lumen endotracheal intubation: A prospective, randomized, double-blind, and placebo-controlled trial. Anesthesiol Res Pract. 2013;2013:236089. doi: 10.1155/2013/236089.

8. Manne GR, Upadhyay MR, Swadia V N. Effects of low dose dexmedetomidine infusion on haemodynamic stress response, sedation and post-operative analgesia requirement in patients undergoing laparoscopic cholecystectomy. Indian J Anaesth. 2014;58(6):726-31. doi: 10.4103/0019-5049.147164, PMID 25624537.

9. Klamt JG, Vicente WV, Garcia LV, Ferreira CA. Hemodynamic Effects of the Combination of dexmedetomidine-fentanyl versus midazolam-fentanyl in Children Undergoing Cardiac Surgery with cardiopulmonary bypass. Rev Bras Anestesiol. 2010 Jul-Aug;60(4):350-62. doi: 10.1016/S00347094(10)70044-1, PMID 20659607.

10. Sheikh TA, Dar BA, Akhter N, Ahmad N. A comparative study evaluating effects of intravenous sedation by dexmedetomidine and propofol on patient hemodynamics and postoperative outcomes in cardiac surgery. Anesth Essays Res. 2018;12(2):555-60. doi: 10.4103/aer.AER_46_18, PMID 29962634.

11. Chattopadhyay U, Mallik S, Ghosh S, Bhattacharya S, Bisai S, Biswas H. Comparison between propofol and dexmedetomidine on depth of anesthesia: A prospective randomized trial. J Anaesthesiol Clin Pharmacol. 2014;30(4):550-4. doi: 10.4103/0970-9185.142857, PMID 25425783.

12. Arain SR, Ruehlow RM, Uhrich TD, Ebert TJ. The efficacy of dexmedetomidine versus morphine for postoperative analgesia after major inpatient surgery. Anesth Analg. 2004;98(1):153-8, table of contents. doi: 10.1213/01. ane.0000093225.39866.75, PMID 14693611.

13. Aantaa R, Jaakola ML, Kallio A, Kanto J. Reduction of the minimum alveolar concentration of isoflurane by dexmedetomidine. Anesthesiology. 1997;86(5):1055-60. doi: 10.1097/00000542-199705000-00008, PMID 9158354.

14. Ji F, Li Z, Nguyen H, Young N, Shi P, Fleming N, Liu H. Perioperative dexmedetomidine improves outcomes of cardiac surgery. Circulation. 2013;127(15):1576-84. doi: 10.1161/CIRCULATIONAHA.112.000936, PMID 23513068.

15. Patel CR, Engineer SR, Shah BJ, Madhu S. Effect of intravenous infusion of dexmedetomidine on perioperative haemodynamic changes and postoperative recovery: A study with entropy analysis. Indian J Anaesth. 2012;56(6):542-6. doi: 10.4103/0019-5049.104571, PMID 23325938.

16. Talke P, Chen R, Thomas B, Aggarwall A, Gottlieb A, Thorborg P, Heard S, Cheung A, Son SL, Kallio A. The hemodynamic and adrenergic effects of perioperative dexmedetomidine infusion after vascular surgery. Anesth Analg. 2000;90(4):834-9. doi: 10.1097/00000539-200004000-00011, PMID 10735784.

17. Kernan S, Rehman S, Meyer T, Bourbeau J, Caron N, Tobias JD. Effects of dexmedetomidine on oxygenation during one-lung ventilation for thoracic surgery in adults. J Minim Access Surg. 2011;7(4):227-31. doi: 10.4103/09729941.85645, PMID 22022111.

18. Lee SH, Kim N, Lee CY, Ban MG, Oh YJ. Effects of dexmedetomidine on oxygenation and lung mechanics in patients with moderate chronic obstructive pulmonary disease undergoing lung cancer surgery: A randomised double-blinded trial. Eur J Anaesthesiol. 2016;33(4):275-82. doi: 10.1097/ EJA.0000000000000405, PMID 26716866.

19. Xia R, Yin H, Xia ZY, Mao QJ, Chen GD, Xu W. Effect of intravenous infusion of dexmedetomidine combined with inhalation of isoflurane on arterial oxygenation and intrapulmonary shunt during single-lung ventilation. Cell Biochem Biophys. 2013;67(3):1547-50. doi: 10.1007/s12013-013-9659-8, PMID 23733668.

Cite this Article : Agarwal S, Verma R, Shukla A, Hemlata, Singh D, Chaudhary AK. Effect of Dexmedetomidine on Hemodynamics in Thoracic Surgery - A Randomized Controlled Study. J. Clin. Res. Applied Med. 2021;1(1):2-6. 